\title{
Correction to: Adaptation and validation of the Cambridge Pulmonary Hypertension Outcome Review (CAMPHOR) for the Netherlands
}

\author{
M. Wapenaar ${ }^{1}$ J. Twiss ${ }^{2}$ M. Wagenaar ${ }^{3}$ P. Seijkens ${ }^{1} \cdot$ L. van den Toorn ${ }^{1}$ J. Stepanous ${ }^{2}$ A. Heaney ${ }^{2}$. \\ A. van den Bosch ${ }^{4}$ K. A. Boomars ${ }^{1}$
}

Published online: 26 October 2018

(c) The Author(s) 2018

\section{Correction to:}

\section{Neth Heart J 2016}

https://doi.org/10.1007/s12471-016-0849-z

Unfortunately the original version of this article contained Electronic Supplementary Material which should not have been published with the article due to copyright reasons.

The original version has been updated and the ESM has been removed.
Open Access This article is distributed under the terms of the Creative Commons Attribution 4.0 International License (http:// creativecommons.org/licenses/by/4.0/), which permits unrestricted use, distribution, and reproduction in any medium, provided you give appropriate credit to the original author(s) and the source, provide a link to the Creative Commons license, and indicate if changes were made.

The online version of the original article can be found under https://doi.org/10.1007/s12471-016-0849-z.

K. A. Boomars

k.boomars@erasmusmc.nl

1 Department of Pulmonary Medicine, Erasmus Medical

University Center, Rotterdam, The Netherlands

2 Galen Research Ltd, Manchester, UK

3 Department of Pulmonary Medicine, VU University Medical Center, Amsterdam, The Netherlands

4 Department of Cardiology, Erasmus Medical University Center, Rotterdam, The Netherlands 